\title{
Research on Big Data Audit Teaching Based on SWOT Analysis
}

\author{
Zhihua Wang \\ Southwest University of Science and Technology, Mianyang 621000, Sichuan Province, China
}

Funding: Southwest University of Science and Technology Undergraduate Education Teaching Reform and Research Project 2019 "Research on Big Data Auditing Teaching Based on SWOT Analysis Method" Project No.: 19XN0029.

\begin{abstract}
This article analyzes the areas that need to be improved in audit teaching from the perspective of big data, uses SWOT analysis to construct a SWOT matrix of big data audit teaching, points out the advantages, opportunities, risks and threats of audit teaching, clarifies the purpose of audit teaching, enriches and perfects the big data Data audit teaching theory promotes the development of higher education auditing profession.
\end{abstract}

Keywords: SWOT; Big data; Audit teaching

Publication date: April, 2021; Publication online: 30 April, 2021

*Corresponding author: Zhihua Wang, 2836883705@qq.com

\section{Introduction}

The advent of the big data era not only brings huge challenges to the audit industry, but also brings huge changes to audit teaching. From the current point of view, the traditional audit teaching model is difficult to adapt to the development of the era of big data. How to meet the changes in the era of big data with a brand-new teaching model is an urgent problem facing the auditing profession in colleges and universities. The challenges brought by the big data era to audit mainly include the following two aspects.

\subsection{Challenges of the audit industry}

The traditional audit model focuses on finding error orientation, which is a kind of after-the-fact supervision. With the development of big data, the orientation of integrating risks into the business and integrating information is gradually formed, and the after-event supervision is adjusted to the incident, and the static audit work is gradually formed. Become dynamic real-time supervision, and turn on-site supervision into remote supervision. For the traditional audit industry, relying only on existing computer audit software cannot meet the needs of big data analysis. In particular, it is a huge challenge for the traditional audit industry to change from a sample audit to a comprehensive and systematic in-depth audit.

\subsection{Challenges of auditors}

With the rapid development of big data, from collecting traditional financial data to non-financial data, how to achieve professional audit data processing has become a difficult problem for current auditors to solve. Computer and data mining technology is particularly important in today's era. Auditors must not only possess compound professional knowledge, but also have the ability to innovate. For example, it has the ability to design audit data processing models and audit data analysis models, and make corresponding preparations for solving the problems encountered in the audit process.

\section{Big data audit teaching SWOT matrix}

The SWOT analysis method is a method of analyzing the competitive situation of enterprises. It evaluates its own advantages, disadvantages, opportunities and threats in external competition to conduct in-depth and comprehensive analysis and positioning of competitive advantages before formulating development strategies. The SWOT analysis method is represented by constructing a SWOT structure matrix, and assigning different analysis 
meanings to different areas of the matrix.

Through the matrix analysis table, four kinds of strategies are obtained, so as to propose constructive ideas for the reform of big data audit teaching. Big data audit teaching should be based on the current actual situation and future development direction to further improve the level of audit teaching and realize the mutual benefit of audit teaching.

\section{SWOT analysis of big data audit teaching}

\subsection{Advantages}

\subsubsection{Teaching data sharing}

Using big data to audit teaching can realize teaching data sharing. Through the construction of a big data audit teaching cloud platform, data collection from major accounting firms is realized, and unified data conversion and cleaning are carried out to become relevant data that is conducive to audit teaching. Through the integration of the unified data caliber, the data model is transformed, So as to realize data sharing.

\subsubsection{The source of teaching data is complete}

The big data audit process includes not only structural data such as accounting statement data, but also non-structured data such as sound and images, so as to achieve full coverage of audit data. With the support of new technologies, relevant data will be generated around big data audit teaching courses, including basic course information, course members, course resources, course assignments, teacher-student interaction, course assessment and other data. On the one hand, the sources of audit data collected by major accounting firms are complete; on the other hand, the sources of teaching data generated in the teaching process are also very complete.

Table 1. SWOT matrix analysis table of big data audit teaching

\begin{tabular}{|c|c|c|}
\hline Internal factors & $\begin{array}{l}\text { Advantage }(S) \\
\text { 1. Teaching data sharing } \\
\text { 2.Complete source of } \\
\text { teaching data } \\
\text { 3. New technology support }\end{array}$ & $\begin{array}{l}\text { Disadvantage }(W) \\
\text { 1.Difficultyin actual } \\
\text { operation } \\
\text { 2. More investment } \\
\text { 3. Data security risks }\end{array}$ \\
\hline $\begin{array}{l}\text { Opportunity (O) } \\
\text { 1. Policy support } \\
\text { 2.Thecontinuous development } \\
\text { of big data }\end{array}$ & $\begin{array}{l}\text { SO Strategy } \\
\text { 1. Use the new big data } \\
\text { technology to establish a } \\
\text { teaching cloud platform to } \\
\text { realize teaching innovation. } \\
\text { 2. Use big data and high-tech } \\
\text { enterprise data to improve } \\
\text { teaching practice. } \\
\text { 3. Use new technology to } \\
\text { support the improvement of } \\
\text { teaching level. }\end{array}$ & $\begin{array}{l}\text { WO Strategy } \\
\text { 1. According to the national big } \\
\text { data support policy, improve the } \\
\text { big data teaching platform. } \\
\text { 2. Seize the opportunity of big } \\
\text { data development and invest a } \\
\text { large number of technical } \\
\text { personnel to control data } \\
\text { security risks. }\end{array}$ \\
\hline $\begin{array}{l}\text { Threat }(\mathrm{T}) \\
\text { 1. Affected by traditional } \\
\text { concepts, audit professional } \\
\text { teachers are not effective in } \\
\text { learning big data technology in } \\
\text { the short term. } \\
\text { 2. Big data teaching platforms } \\
\text { are uneven. }\end{array}$ & $\begin{array}{l}\text { ST Strategy } \\
\text { 1. Use the advantages of big } \\
\text { data teaching data sharing to } \\
\text { change the traditional concept } \\
\text { of audit teachers. } \\
\text { 2.Using new technology } \\
\text { support, choose a high-quality } \\
\text { big data teaching platform. }\end{array}$ & $\begin{array}{l}\text { WT Strategy } \\
\text { 1.Improve the big data teaching } \\
\text { platform to prevent data } \\
\text { security risks. } \\
\text { 2.Regularly check the operation } \\
\text { of the big data teaching } \\
\text { platform to avoid data security } \\
\text { risks. }\end{array}$ \\
\hline
\end{tabular}




\subsubsection{New technical support}

In the process of big data audit, big data will be used for analysis. This new type of analysis method includes five aspects: one is visual analysis, which uses charts to fully display the process of data analysis and the trend of data chain; Build a data mining model from random, irrelevant data to extract valuable and hidden information within the data; the third is the predictive analysis capability, which makes predictive judgments based on the results of visual analysis and data mining; The fourth is the semantic engine, which uses a series of tools to extract, parse and analyze data, and automatically extract information from "document" data; the fifth is data quality and data management, which uses standardized processes and tools to process data to ensure data analysis The quality of the results.

\subsection{Disadvantages}

\subsubsection{Difficulty in actual operation}

Using big data for audit teaching is easy to encounter difficulties in the actual operation process. Unlike traditional teaching, in the process of big data audit teaching, there are complicated applications of high-tech methods such as batch processing, Python, and the cloud. If teachers and students do not have a good computer foundation, it is difficult to master it completely and systematically. Not only does the operation require special training, but also the support of professional technicians in the maintenance of the big data audit teaching cloud platform.

\subsubsection{More investment}

When building a big data audit teaching cloud platform, a large amount of money must be invested. This is because the application of new big data technology is relatively expensive. These costs mainly include 3 aspects: (1) Development costs. One is architecture and design decisions, and the other is integration and end-to-end testing. (2) Maintenance costs. Keep the big data audit teaching cloud platform running well all the time, dealing with complex server issues and so on. (3) Change the cost. In the process design of the big data audit teaching cloud platform, adjustments need to be made according to the actual teaching situation, so change costs will be incurred.

\subsubsection{Data security risks}

During the audit teaching data sharing stage, there are certain risks in data security. Due to the huge amount of data stored in big data and distributed storage, there will be many vulnerabilities, abnormal traffic attacks, information leakage risks, various security risks during transportation, and storage management risks. In particular, the big data audit teaching cloud platform uses real accounting firm case data as the basis for teaching, which will cause certain data security management difficulties.

\subsection{Opportunity}

\subsubsection{Policy support}

With the continuous in-depth development of big data, the government has begun to vigorously support it. When schools build a big data audit teaching cloud platform, they can provide many policy support. For example, the auditing major of Nanjing Audit University (Government Auditing Big Data Course) is a professional expansion of the auditing major under the new social needs. The professional direction is rooted in the traditional auditing major and is positioned to provide talents for the government audit department.

\subsubsection{The continuous development of big data}

In the development of big data, more powerful technical conditions will appear to support the development of auditing professional teaching. For example, new big data technologies, such as Python programming, data mining and machine learning, data analysis and visualization tools, all provide help to the construction of the big data audit teaching cloud platform, and at the same time promote the system innovation of audit teaching.

\subsection{Threat}

\subsubsection{The teaching effect is not obvious}

Under the influence of traditional concepts, many full-time auditors do not have the awareness of emerging big data technologies, and lack knowledge in learning big data technologies, and cannot quickly improve the teaching level of big data auditing in a short period of time.

\subsubsection{Uneven platforms}

Because big data is a new type of technology, the big data audit teaching cloud platforms developed on the market are uneven, which brings many problems to the choice of schools. The school must make choices that meet its own needs and possible options based on its own student resources, faculty, and laboratory equipment, which will bring a series of follow-up questions.

\subsection{Development direction}

In view of the disadvantages and challenges of SWOT matrix analysis of big data audit teaching, the future development direction can be proposed from the following points: 


\subsubsection{Promote the implementation of the big data audit teaching plan}

Colleges and universities should actively strive for resources, accelerate research on big data platforms through government funding, build big data audit teaching cloud platforms, integrate big data audit teaching resources, fully understand big data processing technologies and algorithms, and strengthen research on big data audit teaching curriculum systems. Plan the implementation plan as a whole to promote the implementation of the big data audit teaching plan.

\subsubsection{Reduce the cost of the big data audit teaching cloud platform}

Colleges and universities should organize relevant technical personnel to invest in the research and development of the big data audit teaching cloud platform as soon as possible, discuss in-depth technical aspects of various problems arising in the research and development process. Make comprehensive adjustments from three aspects of R\&D costs, operating costs and change costs, master core technologies to reduce costs, and improve platform efficiency.

\subsubsection{Prevent big data audit data risks}

In response to the data security risks of the big data audit teaching cloud platform, funds and technical personnel are invested in maintenance, and through daily inspections, problems are discovered and resolved in a timely manner. Choose a high-quality big data audit teaching cloud platform, improve the big data audit teaching cloud platform, and prevent possible risks.

\subsubsection{Strengthen the training of professional audit teachers}

Colleges and universities should strengthen the training of professional teachers, and organize teachers to participate in training, so that professionals from enterprises and accounting firms outside the school can come to the school to give lectures., Encourage teachers to self-learn big data processing technology and other ways to strengthen learning, update their own knowledge system, and accelerate the process of big data audit teaching.

\subsubsection{Improve students' interest in learning}

According to the learning characteristics of the new generation of students, develop a learning plan suitable for students to increase students' interest in learning big data audit courses. Through the development of various forms of big data audit teaching cases, students' interest in learning can be cultivated from different aspects.

\section{Conclusion}

Big data audit teaching is particularly important for the reform of audit courses in universities. By improving the teaching of big data auditing, it will promote the in-depth analysis of the existing problems in the current audit teaching from the theoretical, technical, and organizational levels in universities, so that universities can better carry out audit teaching work. This paper conducts a SWOT analysis of big data audit teaching, clarifies the advantages, disadvantages, opportunities and threats of big data audit teaching, and proposes future development directions for the disadvantages and challenges brought by big data to audit teaching. It fully shows that we can use the new big data technology to establish an audit teaching cloud platform, and at the same time, use the national big data support policy to better realize teaching innovation.

\section{References}

[1] Danielle Lombardi, R Bloch.Etc. The current state and future of the audit profession [J]. Current Is-sues in Auditing, 2015, 9(1): 10-16.

[2]Alle Ms, Gra YG. Incorporating Big Data in audits: identifying inhibitors and a research agenda to ad-dress those inhibitors [J]. International Journal of Ac-counting Information Systems, 2016, 22(7): 44- 59.

[3] Cheng Ping, Wang Xudong. ADDIE-based "Internet + Accounting" MPAcc Big Data Intelligent Auditing Ability Cultivation-Taking Chongqing University of Technology MPAcc Education as an Example [J]. Finance and Accounting Monthly, 2018 (21): 41-45.

[4]Yang Jie, Ying Limeng. Auditing big data analysis talent demand and its training — model construction based on the concept of CDIO [J]. Finance and Accounting Monthly, 2019(4): 108-119.

[5]Shen Fanfan, Xu Chao, He Yanxiang, Chen Chen. The realization path of the cultivation of compound audit talents in colleges and universities from the perspective of big data_- Taking Nanjing Audit University as an example [J]. High Education Journal, 2019 (14): 167-170 . 